\title{
CRECHE DA UNIVERSIDADE ESTADUAL DE LONDRINA: questões sobre as práticas educativas*
}

\author{
Beatriz Carmo Lima de Aguiar
}

Mestranda em Educação pela Universidade Estadual Paulista - Campus de Marília.

$\mathrm{O}$ artigo baseia-se em uma pesquisa sobre as práticas educativas da creche da Universidade Estadual de Londrina. Essa pesquisa teve como objetivo repensar o projeto pedagógico da Creche/UEL junto com as educadoras, examinando suas limitações e contribuições.

Analisa como a creche tem sido pensada historicamente, dando ênfase ao caráter assistencialista que marcou o seu surgimento, deixando resquícios até hoje, e discorre sobre a luta da creche com os pais, educadores e toda a comunidade, para ser reconhecida de fato como um espaço legítimo de educação e desenvolvimento da criança.

Palavras-chave: creche; práticas educativas; educação infantil.

$\mathbf{E}$ ste artigo é uma versão reduzida da monografia apresentada por exigência do curso de Especialização em Sociologia e Sociologia da Educação da Universidade Estadual de Londrina. A pesquisa realizada teve como objeto as práticas educativas da creche da UEL. Compreendo que o papel de uma creche não deva ser tão somente prestar assistência, mas sobretudo, educar. Sendo assim, a pesquisa pretendeu verificar como ocorre a educação na creche estudada, objetivando repensar seu projeto pedagógico junto com as educadoras e examinar suas limitações e contribuições. Também procurou refletir sobre a sua atual prática educativa e a relação com a família das crianças que atende. Para atingir tais objetivos foram utilizadas as técnicas de pesquisa participante e exploratória.

Em favor de quem atua diretamente com as crianças - as educadoras - esta pesquisa pretendeu contribuir com elementos que possam subsidiar uma avaliação da educação proposta pela Creche/UEL. Para abordagem do objeto e explicitação do problema utilizei as técnicas de entrevistas abertas e de pesquisa participante com questionário misto. As entrevistas foram realizadas com um grupo de mães, um grupo de educadoras e ainda com mães cujos filhos já estavam desligados da creche em razão da idade. Ao todo foram realizadas 56 entrevistas. A pesquisa foi dividida em quatro tópicos que serão expostos a seguir.

\section{HISTÓRICO DA IMPLANTAÇÃO DAS CRECHES EM LONDRINA}

O histórico engloba o período de 1934 a 1992, passando pela gestão do prefeito Wilson Moreira (1983-1988) e pela gestão de Antônio Belinati (1989-1992).

Para realizar a abordagem da inserção de creches em Londrina, reportei-me ao estudo feito por LÓLIS (1993). Neste, ela faz uma análise teórica e histórica das políticas sociais brasileiras, com ênfase na assistência social. Particulariza a cidade de Londrina, realizando uma análise histórica do surgimento do município e suas questões sociais locais no período de 1934 a 1992. Utilizei, ainda, o relatório elaborado pela Secretaria Municipal de Ação Social de 1934 a1984 (PML, 1984), que completa a análise feita por Lólis.

Logo no início da colonização do município, como afirma LÓLIS (1993, p.51), "parecia não existir a questão social, pois a maioria da população era formada por pequenos proprietários de terras". As pessoas buscavam resolver os problemas em conjunto, "dependiam, portanto, da ajuda mútua e da caridade da Igreja".

O crescente aumento populacional desencadeado na cidade criou necessidades que intimaram o poder público

\footnotetext{
* O texto é uma adaptação da monografia intitulada Concepção de educação da creche da Universidade Estadual de Londrina: questões sobre as práticas educativas, apresentada como trabalho de conclusão do curso de Especialização em Sociologia e Sociologia da Educação, da UEL, em novembro de 1997, sob orientação da professora Raimunda de Brito Batista.
} 
local a definir políticas sociais de caráter coletivo, pois tornou-se impossível para a sociedade civil continuar resolvendo tais problemas.

Desse modo, em 1948 a prefeitura criou o Departamento de Educação Pública e Assistência Social, dando "mais ênfase à área educacional". Nessa ocasião a assistência social era mais voltada para o "atendimento médico-hospitalar, fornecimento de passagens, medicamentos, alimentos, roupas e outros". (PML, 1984, p.1)

Ainda em 1948, buscou-se institucionalizar o atendimento social. Foi criada, então, em 29 de junho, a Associação de Proteção à Maternidade e à Infância (APMI). Esta tinha o propósito de proteger e assistir a maternidade e a infância em geral, priorizando o atendimento à gestante.

Em 1955 foi instituída a Casa da Criança, que era mantida pela APMI. LÓLIS (1993, p.53) a cita como a primeira creche de Londrina. Nela se realizava um trabalho educativo de orientação às mães quanto ao cuidado de seus filhos. Atendia 130 menores de 6 meses a 6 anos, em regime de externato e semi-internato. Esta entidade foi desativada em abril de 1969. As crianças foram transferidas para as creches Nossa Senhora de Fátima e Santa Rita, "objetivando além de outras necessidades o atendimento em instalação mais adequada ao desenvolvimento integral dos menores". (PML, 1984, p.4)

Notei que outras creches foram inauguradas. No entanto, durante anos de existência a finalidade dessas creches e lares limitava-se ao recolhimento de crianças pobres da rua. Mas, a partir da década de 70 , isto se modificou, dadas as mudanças sociais ocorridas no mundo em decorrência das transformações no mercado de trabalho que afetaram a organização familiar causando, o afastamento da mulher de sua função materna. A mulher afastou-se do filho para trabalhar fora de casa, com o desígnio de aumentar a renda familiar. Ela precisava de um lugar para deixar a sua criança, e é por isso que em Londrina, como em todo país, crescce a reivindicação da comunidade por creches. Não se pode esquecer que o movimento de implantação de creches é originário de reivindicações e propostas de movimentos feministas. Sendo assim, nesse momento, as creches foram fundadas para atender a esse direito. GAYOTTO et al (1992, p.23) reforçam isso ao afirmar: "as creches não surgiram para atender as necessidades básicas das crianças de 0 a 6 anos, mas em resposta à necessidade da mulher de inserir-se no mercado de trabalho".

De 1983 a 1988 (gestão de Wilson Moreira) foram construídas 21 creches (3,5 ao ano). LÓLIS (1993, p.80) salienta que "nem todas foram construídas pelo poder público, sendo algumas em sistema de parceria com a sociedade civil, adaptadas a residências ou a centros comunitários. Algumas foram entregues com todos os equipamentos ou parte deles. Projetos de equipamentos e ampliações também foram enviadas à Secretaria do Trabalho e da Ação Social (SETAS) do Estado para obtenção de recursos".

Ainda nesta gestão, a primeira dama do município "atuou junto ao PROVOPAR-LD e nunca se tinha investido tanto em creches e programas de alimentos em conjunto voluntariado como nesta gestão, dividindo com o Departamento de Serviço Social a demanda emergencial e a demanda por creches". (idem, p.85)
Tendo, pois, o encargo da área de creches, o Departamento de Serviço Social (DSS), através do Programa de Atendimento ao Menor, "obteve um avanço com a elaboração de um Projeto Diretor de Creches e Centros de Estudos do Menor e de Integração à Comunidade (CEMICs) onde, com base em dados técnicos, se planejou a instalação destes equipamentos sociais na cidade no período de 1983-1988". (idem, p.89) Tinha-se como meta construir 38 creches para atendimento de crianças de 0 a 6 anos e 35 CEMICs para crianças de 7 a 14 anos.

A meta não foi atingida em sua totalidade. Ao final de 1988, das creches previstas só dezenove haviam sido construídas. Dessa forma, cumpriu-se " $68 \%$ do previsto, havendo uma considerável ampliação na rede de atendimento de 0 a 6 anos". (idem, p.90)

O período da administração seguinte (1989-1992), de Antônio Belinati, subsequiente à "promulgação da Constituição Federal de 1988 e durante o período em que foi elaborada a Lei Orgânica do Município e aprovado o Estatuto dos Direitos da Criança e do Adolescente, Leis que garantiam os direitos de efetivação da cidadania dessa população, foram construídas 11 creches (2,75 ao ano)". (idem, p.80)

Em 12 de dezembro de 1992 foi inaugurado o Centro Integrado de Vivência e Assistência à Criança e ao Adolescente, "super creche" ou "Cidade da Criança", prestando atendimento a mais de 300 crianças. Esta tinha como objetivo atender 500 crianças "e [foi construída] em localização imprópria. Sofreu críticas pelo número de atendimento, que é considerado muito alto para a faixa etária". (idem, p.102)

Vale ressaltar que algumas creches foram edificadas ou equipadas com recursos obtidos por entidades "e que a verba utilizada na construção do Centro Integrado de Vivência da Criança e do Adolescente (Cidade da Criança) daria para construir de 3 a 4 creches". (idem, p.70) Um dado importante, como nos aponta Lólis, é que até esta época, 1992, a Super Creche era a única totalmente municipalizada. (idem, p.80)

A Cidade da Criança está entre os projetos polêmicos da segunda gestão, que passaram via Secretária Geral sem que se realizasse um estudo prévio da sua viabilidade. A creche Cidade da Criança mostra que a "não realização de um estudo da necessidade e das instalações pode inviabilizar uma obra e onerar o caixa público". (idem, p.114)

Como já foi colocado, a creche surgiu para atender um direito da mulher. Mas devo frisar que, acima disso, as creches existem para as crianças e necessitam atender seus direitos como seres humanos. Isto "vai além de serem um depósito de crianças, de serem um local que dá alimento, o local onde ficam as crianças das mães que trabalham." (GAYOTTO et al, 1992, p.28)

Sabe-se que, em sua fase inicial, as creches atendiam a pessoas de pobreza absoluta. Sendo assim, não havia, neste período, a preocupação da creche como instituição educativa. Hoje, já não é suficiente recolher crianças da rua, "abrigá-las e alimentá-las bem, há todo um consenso da sociedade que exige condições de afeto e calor humano". (RIZZO, 1991, p.26) As mulheres precisam de ajuda nos cuidados dos seus filhos, mas também na educação.

Neste contexto, concluí que durante o período de 1934 a 1992 as creches de Londrina organizaram seu espaço em 
função de idéias de assistência e custódia da criança, ficando sua implantação por iniciativa da comunidade. Isso, apesar de a Constituição de 1988 definir a creche como direito da criança de 0 a 6 anos de idade e dever do Estado.

Apesar da determinação da Constituição, na segunda gestão de Antonio Belinati não houve aumento no número de creches da cidade. Porém, convém lembrar que não é suficiente haver acréscimo de creches em Londrina, mas esse aumento no número deve vir acompanhado de atendimento com qualidade para o bom desenvolvimento da criança.

\section{CRECHE: ASSISTENCIALISMO OU FUNÇÃO PEDAGÓGICA?}

O levantamento realizado por LÓLIS (1993), o relatório da Secretaria Municipal de Ação Social de 1934-1984 (PML, 1984), o referencial bibliográfico e a pesquisa levaram-me a pensar que construir uma proposta pedagógica para a creche é um desafio. No entanto, acredito que é necessário enfrentá-lo, a fim de que se avance além da concepção assistencialista que historicamente tem caracterizado o atendimento à criança. Nesse sentido, as creches devem se estabelecer em princípios ligados a uma visão de criança como ser ativo, que constrói conhecimento sobre si e sobre o mundo que a cerca e não apenas como um ser que necessita de abrigo e de alimento, tendo a sua educação negligenciada.

A creche tem sido pensada historicamente com ênfase no caráter assistencialista. Mas observa-se, também, a luta desenvolvida pela creche em conjunto com os pais, educadores e toda a comunidade para ser reconhecida de fato como um espaço legítimo de educação e desenvolvimento da criança. Evidencia-se, ainda, o fato de a Creche/UEL ter essa consciência de compartilhar com a famúlia a educação das crianças. $\mathrm{O}$ primeiro ambiente próprio para a educação da criança é o ambiente doméstico. Mas, outro contexto a ser considerado para o desenvolvimento infantil é a creche.

A palavra creche, de origem francesa, significa "manjedoura" e foi "utilizada para designar a primeira instituição criada pelo padre Oberlin, na França, há mais de duzentos anos, para guardar e abrigar crianças pequenas consideradas necessitadas pela sociedade da época". (ABRAMOWICZ \& WAJSKOP, 1995, p.9)

No Brasil, até a década de 40 , as creches organizavam seu espaço e seu cotidiano em função de alimentar, higienizar e dar segurança física às crianças, isto é, possuíam um caráter assistencial. A sua prática não era, portanto, voltada para a educação, para o desenvolvimento intelectual e afetivo das crianças.

Para situar devidamente o leitor, convém conceituar assistencialismo. De acordo com ALAYÓN (1992, p.48), "o assistencialismo é uma das atividades sociais que historicamente as classes dominantes implementaram para reduzir minimamente a miséria que geram e para perpetuar o sistema de exploração. Essa atividade foi e é realizada com matizes e particularidades, em consonância com os respectivos períodos históricos, em nível oficial e privado, por leigos e religiosos. A sua essência foi sempre a mesma (à margem da vontade dos 'agentes' intervenientes): oferecer algum alívio para relativizar e travar o conflito, para garantir a preservação de privilégios em mãos de uns poucos".

É a esse conceito que me referi ao afirmar que as creches possuíam um cunho assistencialista, pois elas surgiram como meios paliativos para a sociedade, para tirar crianças pobres e órfãs das ruas. A idéia de creche está, então, intimamente ligada a essa noção de assistencialismo.

Ressalto, no entanto, que ao trabalhar em minha pesquisa com a Creche/UEL também a vejo como assistencialista. Estou me referindo às ações que as educadoras desenvolvem em proveito das crianças, tais como: ensinar a lavar as mãos, o rosto, escovar os dentes, trocar fraldas, dar banho, trocar de roupa, dar as refeições, mamadeiras, papinhas, ensinar a criança a comer sozinha, etc.

Decidi utilizar essa definição de assistencialismo para a Creche/UEL porque percebi, em seu cotidiano, que era dessa maneira que as educadoras entendiam o trabalho realizado. Vale lembrar, ainda, que dentro deste conceito que aplico à Creche/UEL, todas as creches são assistencialistas. No entanto, um ponto no qual a UEL difere das demais é que ela não lida com subempregados, com miseráveis; ela atende à camada média (econômico-social e culturalmente). A Creche/UEL tem o caráter assistencialista pelo fato de as famílias delegarem o ato de educar à creche. Entendo que a educação é responsabilidade e função da família. Cabe à creche apenas complementar essa função trabalhando em conjunto com a família.

Mas, o que se entende por creche? Entende-se que é um dos contextos possíveis de desenvolvimento da criança. Além de prestar cuidados físicos, "ela cria condições para o seu desenvolvimento cognitivo, simbólico, social e emocional". (OLIVEIRA, 1992, p.64)

A partir da década de 80 , por iniciativa de movimentos populares, iniciaram-se no Brasil debates sobre a função da crèche para a sociedade moderna. Nesse momento, a creche passa a ser pensada e exigida como um lugar de educação coletiva das crianças, e se constata a necessidade de extinguir a visão assistencialista com a qual sempre foi identificada.

Obteve-se, a partir da Constituição Brasileira de 1988 , a conquista da creche "como direito da criança de zero a seis anos de idade e dever do Estado o atendimento em creche e pré-escola". (ABRAMOWICZ \& WAJSKOP, 1995, p.9) A creche passa a ser também uma reivindicação de homens e mulheres, uma vez que os filhos são de responsabilidade de ambos os sexos.

Dessa forma, pode-se observar que é recente conceber a creche desempenhando um papel educativo. Foi preciso todo um movimento histórico que possibilitasse alterações na forma de conceber a criança, seu desenvolvimento e as funções da famúlia.

Nota-se, portanto, que o significado da creche vem se modificando e suas funções estão sendo redefinidas. Ao avançar sobre a questão do assistencialismo afirma-se a identidade da creche, ou seja, reconhece-se a evolução das práticas e crenças sobre o cuidado da criança e reconhece-se tam- 
bém a creche como área legítima de educação e crescimento da primeira infância.

Cabe, no momento, a seguinte pergunta: quais as vantagens de ter um filho na creche, hoje? A creche dispõe "de um potencial que pode constituir em significativo sistema de apoio para as relações familiares, pois: retira a família de seu isolamento; liberta a mulher da rotina do trabalho doméstico e da renúncia às suas próprias necessidades em serviço dos filhos; aumenta significativamente as fontes de identificação da criança; e ainda permite aos pais desfrutar seus filhos com mais prazer sem tornaremse necessariamente as únicas figuras de autoridades em relação a eles". (HADDAD, 1991, p.230-231) É obvio que o reconhecimento dessas qualidades, dessas vantagens, vai depender de uma profunda revisão dos nossos conceitos de infância, educação, família e sociedade. É inegável, diante de tal assertiva, a contribuição que a creche dá para a socialização da criança. Durante as entrevistas, $100 \%$ das mães, afirmaram que a creche contribui para a sociabilidade de seus filhos.

A creche surgiu marcada pelo assistencialismo. Entendo que o objetivo da creche assistencialista não é compartilhar dos cuidados da criança e sim apropriar-se dela, uma vez que a creche considera as mães incompetentes para cuidar de seu filhos; só ela é boa, eficiente, não aceitando nenhuma intervenção das mães. Sua preocupação primeira era abrigar crianças carentes, orfãs que se achavam nas ruas, e de certa forma escondê-las da sociedade. Durante muito tempo dentro dessa dimensão, a creche era apresentada como uma "caridosa" substituta materna e assim definia a sua identidade: "completando a ação para qual o outro não tem competência". (idem, p.102)

Nessa concepção que se estende, para muitos, até os dias de hoje, a creche foi criada para crianças pobres. Porém, hoje é fato que pessoas de diferentes camadas possuam. filhos em creches. Assim, essa concepção está aos poucos se desfazendo e sabe-se que muitas famílias consideram cômodo delegar a educação de seus filhos a uma creche, como foi constatado nos depoimentos.

Na monografia, transcrevi a opinião das educadoras e mães sobre a questão de compartilhar a educação das crianças. Minha conclusão é que a Creche/UEL já deu um grande passo para que isso se concretize, diferentemente do que fazem muitas creches que tentam substituir a família e não compartilhar a responsabilidade de educar. Percebo ainda que a Creche/UEL tenta compartilhar, mas algumas mães não percebem isto. Outras, que julgo já terem adquirido consciência do papel da creche, querem mais espaço para dialogar, para discutir. Julgo, portanto, que a creche não substitui a família. Creche e famúlia são instituições que se completam e assim devem ser compreendidas.

\section{A FUNDAÇÃO DA CRECHE/UEL}

Retrato aqui a dificuldade que houve para que a Creche/UEL fosse fundada. Realizo uma caracterização detalhada desde o período de sua implantação (1992), colocan- do como estão hoje os espaços que foram readequados para atender à demanda.

Como em todo Brasil, ocorreu também na Universidade Estadual de Londrina a reivindicação dos servidores por uma creche. Havia necessidade de atender o direito da mãe à creche e o direito da criança de ter um ambiente que auxiliasse e estimulasse o seu desenvolvimento nos primeiros anos de vida.

O local escolhido foi o extremo oeste do campus universitário, próximo ao Colégio de Aplicação, por "ser considerado um local silencioso, e oferecer segurança por estar de certa forma afastado do trânsito". (UEL, 1988, p.4-5)

MACHADO (1995) fez um estudo do histórico da implantação da Creche/UEL. Tomarei por base seu trabaIho. De acordo com dados levantados por esta pesquisado$\mathrm{ra}$, os “jornais da época retratam o período de 84 a 90 como intenso nas reivindicações em torno da creche, levantada em greves e movimentos sindicais". (MACHADO, 1995, p.27)

A reivindicação pela Creche/UEL durou em torno de vinte anos. Nesse período, alguns encaminhamentos foram realizados como, por exemplo, uma comissão para elaborar o projeto de implantação da creche. Esta era "presidida pela professora Lídia Maria Monteiro Rodrigues da Silva, do Departamento de Serviço Social, e composta pelos docentes Margareth Villari, Enfermagem; Maria do Socorro Oliveira, Materno-Infantil e Saúde Comunitária; Marília Freitas, Educação; Sônia Sella, Psicologia Social e Institucional; Ângela Pereira Teixeira Victória Palma do Departamento de Ginástica, Recreação e Dança e Betty Elmer Finatti, Assistente Social do Núcleo de Bem-Estar da Comunidade - NUBEC, constituída a partir da portaria no 48.072/90 de 19/09/90". (MACHADO, 1995, p.39-40) A referida Comissão delimitou equipamento, proposta de funcionamento e pessoal necessário para atuar na creche.

Segundo MACHADO (1995, p.41), o Projeto de Implantação da Creche da Uel, buscou "fundamentar e justificar política e tecnicamente a elaboração de diretrizes gerais e serviços a serem prestados". Dentre os diversos itens exigidos para a implantação, a proposta analisou "a concepção de creche e, consequientemente dos serviços prestados, expressos na distribuição do espaço físico, enfatizando o aspecto educativo desta instituição como uma das formas para a garantia de qualidade do trabalho educacional". (MACHADO, 1995, p.41-42)

Esse grupo possuía uma concepção de criança como "ser organizado e competente, adaptado às exigências de cada fase de sua vida (...) disposta ao contato social com adultos e crianças" e "considerou o homem como essencialmente social - medializado pelo conhecimento e pelas relações que estabelece em seu meio apoiando-se nos princípios interacionistas da educação". (UEL apud MACHADO, 1995, p.43) Ainda, como afirma Machado, "parece ser exatamente neste ponto que a creche universitária destacou-se das existentes: uma proposta pedagógica bem clara e sucinta já delimitada em seu projeto, assegurando, através da prática, a legitimidade da função educativa". (MACHADO, 1995, p.43)

Por causa dessa visão do grupo citada acima, foi exigido das assistentes de creche o $2^{\circ}$ grau completo, dando-se primazia ao Magistério de $1^{\circ}$ grau. Essa preferência está vin- 
culada à concepção de creche adotada, uma vez que esta está voltada para uma ação educativa, voltada para o desenvolvimento infantil.

Segundo constatei, três educadoras não possuem essa formação específica, o que não impede o bom desempenho de suas funções. A creche dispõe então de 57,9\% de educadoras com $2^{\circ}$ grau, de $5,3 \%$ com $3^{\circ}$ grau incompleto; de $21,1 \%$ com $3^{\circ}$ grau completo nas seguintes áreas: uma em Administração, uma em Letras, uma em História, uma em Ciências Sociais, duas em Educação Física; e 15,8\% $\operatorname{com} 3^{\circ}$ grau em curso nas seguintes áreas: duas em Serviço Social, uma em Comunicação Social (Jornalismo e Relações Públicas). Há ainda uma especializando em Sociologia e Sociologia da Educação.

Após muitas lutas, o prédio foi entregue à UEL no final de fevereiro de 1991 pela Construtora Cauanã, necessitando apenas "providenciar cerca, gramado, acesso, estacionamento e torre de energia". (CINCO CONSTRUÇÕES..., 1991, p.3) No entanto, a creche foi inaugurada às 10 horas do dia 16 de junho de 1992 pela reitora em exercício, Luzia Deliberador, atendendo trinta crianças nos berçários. A creche é uma divisão do Núcleo de Bem-Estar da Comunidade (NUBEC) e está diretamente ligada à administração da UEL.

MACHADO (1995, p.53) enfatiza que nessa "busca de uma identidade educacional para a Creche/UEL, a presença do Conselho Consultivo demonstrou-se decisiva", pois este, além de organizar o curso de treinamento de funcionários, foi responsável também pela elaboração da Proposta Pedagógica da Creche. De acordo com esta proposta a educação na creche "deve ser essencialmente lúdica, prazerosa, fundada nas mais variadas experiências e no prazer de descobrir a vida". (UEL, 1993, p.7)

A Proposta Pedagógica perdurou no primeiro ano de funcionamento como norteadora de toda a prática desenvolvida na creche. Mais tarde, transformou-se no Projeto Pedagógico, sendo este sistematizado pcla equipe de pedagogos da creche. O projeto pedagógico será mostrado no último tópico.

Ao completar o seu primeiro ano, a Creche/UEL atendia a 75 crianças, já ultrapassando o limite previsto no projeto original (setenta crianças). Apesar de estar funcionando há pouco tempo, já era "considerada modelo na região". (A CRECHE DA UEL..., 1993, p.1) Em 2 de agosto de 1993 a última fase de implantação se efetiva com a abertura da sala 4 (crianças de 4 anos a 4 anos e 11 meses). A partir desta última fase a creche passa a atender 91 crianças, chegando quase à sua capacidade máxima, 100 crianças. A demanda nessa época já era alta. De acordo com um demonstrativo feito pela Divisão da Creche no NUBEC, afirmava-se "existir na UEL cerca de 180 crianças registradas na CRH que não são atendidas pela Creche por falta de vagas". (CRECHE FAZ UM ANO..., 1993, p.3)

A Creche/UEL, nesse primeiro ano de existência, recebeu muitas visitas de outras universidades, alunos da UEL, diretores de outras creches de Londrina e região e até de São Paulo. Tornou-se modelo pela sua "infra-estrutura e organização". (LEÃO, 1993) Recebeu elogios pela sua higiene impecável e por distinguir-se dos "depósitos de crianças" com os quais todos estavam acostumados, e por seguir a linha teórica do construtivismo.

A creche passou a ter, no ano de 1993, uma nutricionista, e alguns projetos que foram realizados vieram enriquecer a sua dinâmica.

Em março de 1993, iniciou-se o projeto de musicalização infantil, coordenado pelas professoras Rose Ana Carvalho e Helena Ester Loureiro do Departamento de Música. Este tinha como objetivos o desenvolvimento da linguagem, a socialização, trocas afetivas e atividades psicomotoras. No questionário proposto a 29 mães, todas elogiaram este trabalho e enfatizaram que o projeto é mais perceptível em casa, pois as crianças em suas brincadeiras cantam muito. Todas as mães deram nota 10 .

A creche contou também com as estagiárias do curso de Psicologia, que na época desenvolviam trabalhos de inter-relacionamento pessoal com as assistentes e de desenvolvimento da criança. Atualmente elas fornecem fichas de avaliação do desenvolvimento individual de cada criança. As educadoras preenchem esta ficha e devolvem para a chefia. As estagiárias analisam e intervêm com as educadoras ou com a família quando a criança está muito aquém do desenvolvimento esperado para aquela faixa etária. As estagiárias ainda prestam atendimento de orientação às mães, quando solicitadas.

No ano de 1995, há o início do projeto de artes plásticas visando desenvolver a parte lúdica das crianças, sua criatividade com brinquedos de sucata e a possibilidade de utilizarem matérias-primas como, por exemplo, a argila.

Nesse mesmo ano, a creche passa a contar com o projeto de extensão da Bebê-Clínica. Este começou no dia $1^{\circ}$ de agosto tendo a odonto-pediatra Karina Correia Bonalumi como estagiária atendendo durante doze horas semanais.

Em 1996 o Projeto de Extensão sobre Educação Sexual em Instituição Educacional foi iniciado na creche. Neste, as educadoras aprenderam conceitos, classificação e objetivos da educação sexual, formas de responder aos questionamentos das crianças e noções fundamentais sobre como proceder nas explicações da sexualidade humana.

Enfim, foram muitas as reivindicações e lutas para que a Creche/UEL fosse implantada. As pessoas engajadas neste processo acreditaram em um sonho: ter uma creche de qualidade. Assim, ela já surgiu marcada por grupos de pessoas de várias disciplinas que se uniram para pensar o seu papel educacional e a importância de ter um lugar que assegurasse à criança o desenvolvimento de suas capacidades. Nota-se que as adequações realizadas desde a sua fundação serviram para melhor atender parte da demanda existente.

Todos os projetos citados contribuíram e contribuem para a aquisição de novos conhecimentos, novas experiências e o desenrolar de potencialidades.

Portanto, acredito que o fato de a Creche/UEL se encontrar dentro de uma instituição de ensino, possibilita toda a infra-estrutura para a inserção de um trabalho pedagógico circunspecto, efetuação de projetos de extensão que enriqueçam essa prática diária e ainda a execução de cursos de aperfeiçoamento para as educadoras, que lhes possibilitem o repensar das suas práticas educativas. 


\section{AS PRÁTICAS EDUCATIVAS DA CRECHE/UEL}

Analisei as práticas educativas da Creche/UEL, tentando mostrar como a parte educacional tem sido vista pelas educadoras e pelos pais e procurando demonstrar os benefícios que ela trouxe para às crianças que foram desligadas por idade, no ingresso à escola. Este tópico enfatiza também como as educadoras visualizam e entendem o projeto pedagógico da Creche/UEL. Nele, temos a linha educacional que a creche deve seguir e a avaliação que as educadoras fazem do seu trabalho pedagógico, ou seja, da sua ação e prática educativa.

Cabe no momento a seguinte questão: qual a utilidade de um projeto pedagógico no cotidiano da creche? Sua validade é mostrar que aquela creche está preocupada com a educação da criança que a frequienta. E vai além, pois tem o papel de nortear o trabalho das educadoras, ou seja, a sua prática educativa e explicitar qual é a linha educacional que a creche segue. FERRETTI (apud UEL, 1994, p.6), afirma que "tendo a interdisciplinaridade como fator preponderante nas ações educacionais, é indispensável considerar a estruturação de um projeto educacional com uma concepção totalizadora da educação".

A Creche/UEL tornou-se diferenciada por dispor de um projeto pedagógico, evidenciando assim o seu interesse com a educação. É a única creche de Londrina com essa característica.

Como já foi dito no tópico anterior, o projeto pedagógico da Creche/UEL tem seus fundamentos formulados na proposta feita pelo Conselho Consultivo, sendo sistematizado pelos membros da equipe pedagógica na gestão 1992-1994.

Dentre as funções do Conselho Consultivo está: contribuir para o perfeito funcionamento da creche, apreciar e emitir pareceres técnicos quanto à dinâmica da instituição. (UEL, 1995, p.21)

Desde a sua formação, o Conselho Consultivo "entendeu que a creche se constitui uma realidade única, instigante e solicitadora de atitudes que exigem criatividade, interesse, empolgação com a tarefa de educar e ousadia no sentido de visualizar e experimentar caminhos não trilhados anteriormente". (UEL,1994, p.2)

Essa proposta postula, como princípio, que a natureza da Creche/UEL não seja assistencialista, ou seja, não pretende ser "um depósito de crianças". Tem como ponto de partida, segundo ROSEMBERG (apud UEL, 1994, p.3), “o entendimento de que a índole do trabalho desenvolvido na Creche/UEL é de natureza educacional, pois ela não existe para substituir a família no atendimento biopsicossocial e afetivo das crianças. Existe, isto sim, para desenvolver uma proposta educativa que considere todos os aspectos do desenvolvimento infantil".

Assim, esta proposta pedagógica com a qual simpatizou o Conselho Consultivo possuía como uma das linhas mestras o desenvolvimento do senso crítico, da liberdade, da solidariedade e do compromisso. A criança não vai ser considerada uma tábula rasa. Nesse contexto, "a educação assume contornos que privilegiam o educando, suas vivências, seus valores e forma de agir (frutos da cultura); e tem uma visão de homem centrada na experiência, na vida e na atividade". (UEL, 1994, p.3) Essa formulação vem ao encontro da idéia de FREIRE (apud GOMES, 1985, p.43) em sua definição do homem como sujeito, agente da história, relacionando-se ativamente com o mundo. No entanto, este homem pode acomodar-se ao seu mundo como simples animal. A educação pode auxiliar o homem a ser sujeito, mas não qualquer educação, e sim uma educação crítica, direcionada à tomada de decisões, que impulsione a autonomia e a responsabilidade social e política. Essa educação é baseada no diálogo e não no monólogo.

Vale colocar a minha compreensão de educação, baseada em Paulo Freire. Entendo por educação, "um ato dinâmico e permanente de conhecimento centrado na descoberta, análise e transformação da realidade pelos que a vivem". (OLIVEIRA \& OLIVEIRA, 1983, p.19) Esse conceito tem a ver com a proposta da creche porque o construtivismo também está centrado na descoberta, a criança constrói o conhecimento. É dinâmico também porque a criança é um ser ativo, é sujeito de suas ações e interações. Estas concepções encontram-se porque ambas acreditam que a educação deve ser prazerosa, respeitando o indivíduo, sua história de vida. Não deve ser uma educação imposta.

Dessa forma, as ações pedagógicas desenvolvidas têm como fundamentação os seguintes princípios: "educação ativa e relacionada com os interesses da criança; ênfase na aprendizagem através da resolução de problemas; ação educativa ligada à vida e não entendida como preparação para a vida e fomento da solidariedade em vez de concorrência". (UEL, 1994, p.3)

A linha teórico-educacional utilizada pela creche é a construtivista-interacionista. A creche é compreendida como o local, "onde se visualiza o indivíduo como construtor de seu próprio conhecimento, através das interações estabelecidas com o meio, dentro de uma concepção histórico-crítica, ou seja, valorizando o processo histórico para o desenvolvimento do mesmo". (idem, p.5)

Após ter colocado as idéias principais do projeto pedagógico da Creche/UEL, observo, de acordo com os dados levantados, como as educadoras e as mães visualizam esta proposta educacional da creche. No decorrer deste levantamento estarei retomando o referido projeto, a fim de avaliá-lo.

Perguntei às educadoras se elas tinham um entendimento claro do projeto pedagógico e de que forma era esse entendimento. De acordo com as respostas obtidas, $42,1 \%$ das educadoras afirmaram que têm um entendimento claro do projeto pedagógico, ao passo que $57,9 \%$, ou seja, a maioria, dizem não ter tal entendimento. Em ambos os casos, tanto no grupo que respondeu afirmativamente à questão quanto no que respondeu negativamente, encontram-se muitas educadoras que afirmaram ter lido o projeto há muito tempo.

Verifiquei que das dezenove educadoras entrevistadas, $73,7 \%$ leram o projeto pedagógico e $26,3 \%$ não o leram. Um outro aspecto levantado foi se elas recorreram ao que leram em busca de elementos que iluminassem a sua 
prática. Pelas respostas verifiquei que, das dezenove educadoras entrevistadas, quatorze não recorreram ao projeto pedagógico da Creche/UEL.

Busquei saber junto às educadoras se elas entendiam qual a linha educacional da creche, solicitando que, na medida do possível, explicitassem sua opinião. Das entrevistadas, treze afirmaram que entendiam e seis afirmaram que não.

Os depoimentos evidenciam que para todas essas educadoras a linha educacional da creche não está bem delineada na prática, ao passo que na teoria nota-se que todas elas sabem que a filosofia educacional da creche pesquisada propõe o construtivismo. Percebi ainda a dificuldade que elas têm de romper com o ensino tradicional, onde o professor - não educador - mostra como fazer, vale dizer, ele é mais direcionador. Mesmo assim as educadoras tentam, se esforçam. Mas encontram um outro obstáculo que não deixa o construtivismo fluir: falta conhecimento, tempo para buscar novas atitudes, novas posturas, tempo para pesquisar e refletir como melhorar a sua prática educativa. Muitas, na realidade trabalham com o que sabem, testam um ou outro elemento e vêem se dá certo com a criança ou não; mesmo experimentando novos caminhos elas ainda se preocupam em trabalhar dentro do pouco que sabem sobre o construtivismo.

Em meu entendimento é fundamental que a creche priorize a formação dos recursos humanos. De acordo com GAYOTTO et al (1992, p.78), o educador precisa de preparo "para ser capaz de criar condições para que o educando aprenda fazendo, tenha suas necessidades atendidas, e haja um objetivo a ser alcançado pelo processo educativo. $\mathrm{O}$ educador deverá adquirir subsídios teóricos que o instrumentem para exercer um papel com autoridade (sem autoritarismo)".

Perguntei às educadoras se elas acreditam que as práticas educativas da creche correspondem à concepção de educação do projeto pedagógico.

De acordo com a observação realizada, verifiquei que as práticas educativas atendem em termos, pois existe uma série de elementos a serem rediscutidos, retrabalhados, entendidos para que o projeto pedagógico seja realmente colocado em prática na sua totalidade.

Procurei saber, ainda, com as dezenove educadoras entrevistadas, quais as dificuldades com que se defrontavam em sua profissão e quais os seus anseios.

Alguns elementos foram muito citados: salário melhor; mais propostas de atividades; cansaço em trabalhar todos os anos com os mesmos temas; falta de perspectiva dentro da creche quanto à promoção; refeitório para funcionárias; carga horária de quatro ou seis horas diárias, pois julgam o trabalho cansativo; melhor relacionamento com os pais; ansiedade em relação a acertos e desacertos; que se cobre mais a parte educacional e menos a assistencial; que a creche tenha cada vez mais qualidade; que se consiga passar mais informações para as crianças; aquisição de mais conhecimentos; e que as educadoras e a creche rompam com a barreira do tradicionalismo

Passarei a relatar agora os dados colhidos junto às 29 mães. Acredito que as mães entrevistadas têm condições de avaliar o trabalho educacional da Creche/UEL, já que possuem filhos nesta instituição há tempo considerável.
Informei-me também com essas mães sobre qual sala a criança freqüenta, pois percebi no cotidiano da Creche/ UEL que a visão de algumas mães com relação à parte educacional muda e a preocupação se intensifica mais na atividade final, ao passo que para as mães com filhos na atividade inicial a questão educacional ainda é pouco percebida.

Investiguei, com as mães entrevistadas, a respeito de sua concepção de educação. Entre os elementos citados destacam-se: ter bons modos, saber se comportar, formar-se cidadão, respeitar o que é do outro, saber dividir o espaço e respeitar a diversidade.

Acredito que a creche deva ter uma educação flexível e que leve em conta a natureza da criança. De acordo com GAYOTTO et al (idem, p.31), a criança de creche ou não é uma "criança cognoscente, uma criança que conhece. A criança sente, pensa, sofre, se alegra ou se entristece, se satisfaz ou se frustra, com ou sem educador de creche". Essa criança precisa de "um educador que a atenda em sua natureza, como um ser com direito à liberdade de expressar-se como pessoa que é".

Perguntei às mães como era o seu relacionamento com as educadoras e o que consideravam de positivo ou negativo nesse relacionamento. Obtive as seguintes respostas: relacionamento de amizade, relacionamento profissional, de respeito, distante porque a mãe sempre está com pressa, ótimas porque as educadoras desenvolvem muito bem o trabalho, são educadas, bem qualificadas, disponíveis para discutir sobre os filhos e prontas a ajudar, o carinho que demonstram é muito importante.

A relação entre creche e família, como se constata em muitos trabalhos, é conflituosa. A Creche/UEL também não foge a esta realidade, mesmo tendo todas as mães entrevistadas colocado que se relacionam bem com as educadoras.

Exporei agora ofeedback dado pelas mães que possuem filhos desligados da creche em razão da idade. As entrevistas foram realizadas apenas com oito mães devido à dificuldade de contato. Os depoimentos evidenciam os agradecimentos e as contribuições da Creche/UEL na vida destas crianças. Perguntei se elas consideravam que a permanência na creche resultou em benefícios para os seus filhos e, se em caso afirmativo, quais eram esses benefícios, e como se deu o desenvolvimento da criança ao ingressar na escola. Verifiquei que para estas mães o trabalho pedagógico, sua rotina diária e as atividades desenvolvidas, contribuíram para o crescimento educacional das crianças.

Indo já para o final do artigo, noto que poucas mães admitiram não acompanhar o filho em seus trabalhos na creche. A realidade, porém, mostra que são poucas as que realmente se preocupam, questionam, colaboram.

Constatei que a mãe geralmente não tem tempo para discutir com o filho como foi o seu dia, nem tempo para conversar com a educadora sobre o que poderá fazer para melhorar o desenvolvimento educacional da criança e dinamizar suas potencialidades. São raros os casos em que a mãe e o pai chegam em casa e dedicam tempo para o filho, tempo para trabalhar a convivência antes que ele durma. São raros os pais que fazem atividades educativas em casa, conversam sobre os temas e estimulam o filho. 
Observei que a Creche/UEL tenta compartilhar com a família a educação de seus filhos; no entanto, novamente é a minoria que participa. Tenho consciência de que são poucas as reuniões com esse objetivo. A creche deve ampliar este espaço de interação, criar maneiras de incentivar a participação dos pais.

Acredito que a filosofia da creche /UEL no seu aspecto educativo, baseado no projeto pedagógico, contribuiu para que as educadoras tivessem essa visão de desempenhar uma função educativa também. Esse conceito foi trabalhado muito e de certa forma está incutido em todas. Nota-se que elas querem fazer mais pelas crianças, querem cursos para trabalhar melhor, exigem tempo para repensar sua postura como educadoras, sua prática e projeto pedagógico.

Para tanto, algumas condições se fazem necessárias: treinamento em serviço, reconhecimento do seu caráter profissional pelos pais, ou seja, não querem ser vistas como substitutas da mãe, enquanto esta trabalha, nem como babás; elas são educadoras infantis; reivindicam seis horas a fim de ter mais tempo para elaborar atividades e buscar mais conhecimentos, pois julgam fatigante trabalhar oito horas diretas com a criança.

Finalizando, é preciso somar forças: creche e família devem caminhar juntas, sem competição. São instituições diferentes e assim devem ser compreendidas. Tem-se que aproveitar esse desejo, essa consciência das educadoras em querer fazer mais pelas crianças e dar a elas capacitação e condições para que efetuem o projeto pedagógico da creche. Tem-se que trazer os pais para o cotidiano e para a vida da creche, incentivando o diálogo destes com o filho sobre o trabalho educacional desenvolvido. Desse modo, esse trabalho terá cada vez mais qualidade, pois são as educadoras juntamente com as crianças que fazem com que a educação aconteça.

\section{REFERÊNCIAS BIBLIOGRÁFICAS}

ABRAMOWICZ, Anete \& WAJSKOP, Gisela. Creches: atividades para crianças de zero a seis anos. São Paulo: Moderna, 1995

ALAYÓN, Norberto. Assistência e assistencialismo: controle dos pobres ou erradicação da pobreza? São Paulo: Cortex, 1992.

A CRECHE DA UEL comemora um ano. Boletim Notícia da UEL. Londrina, n.576, p.l, 1993.

CINCO CONSTRUÇÕES quase na reta final. Boletim Notícia da UEL, Londrina, n.510, p.3, 1991.

CRECHE FAZ UM ANO, e já é modelo. Boletim Notícia da UEL. Londrina, n.510, p.3, 1991

GAYOTTO, Maria L.C.; Rosa J. Langer; Maria A.F. Campos et al. Creches: desafios e contradições da criação da criança pequena. São Paulo: Ícone, 1992.

GOMES, Candido. A educação em perspectiva sociológica. São Paulo: EPU, 1985.

HADDAD, Lenira. A creche em busca de identidade. São Paulo: Loyola, 1991.

LEÃO, Silvana. "Com quem fica o bebê?". Folha de Londrina. Folha da Sexta. Londrina, 2 abr.1993, p.4-5.

LÓLIS, Dione. A pobreza em Londrina: ações do órgão municipal de assistência social. Londrina: UEL, 1993. Monografia (Especialização em
Estado e Políticas Sociais) - Universidade Estadual de Londrina, 1993.

MACHADO, Terezinha de Paula. Creche universitária: um sonho que se fez realidade. Londrina: UEL, 1995. Monografia (Especialização em Metodologia da Ação Docente) - Universidade Estadual de Londrina, 1995.

OLIVEIRA, Rosiska Darcy de \& OLIVEIRA, Miguel Darcy de. "Pesquisa social e ação educativa: conhecer a realidade para poder transformála”. In: BRANDÃO, C.R. (org.). Pesquisa participante. São Paulo: Brasiliense, 1983.

OLIVEIRA, Zilma de Moraes. Creches: crianças, faz de conta \& Cia. Rio de Janeiro: Vozes, 1992.

PML-PREFEITURA MUNICIPAL DE LONDRINA. Assistência e serviços sociais no município de Londrina - histórico: 1934-1984. Londrina, 1984.

RIZZO, Gilda. Creches: organização, montagem e funcionamento. 3.ed. Rio de Janeiro: Francisco Alves, 1991.

UEL-UNIVERSIDADE ESTADUAL DE LONDRINA. Assessoria de Planejamento e Controle. Ficha técnica referente ao projeto de implantação da creche no campus da UEL. Londrina, 1988.

Proposta pedagógica da creche. Londrina: UEL, 1993.

Projeto pedagógico da creche. Londrina: UEL, 1994.

Manual informativo. Londrina: UEL, 1995.

Rev. Mediações, Londrina, v. 4, n. 1, p. 60-67, jan./jun. 1999 